\title{
Global trends and patterns of commercial milk-based formula sales: is an unprecedented infant and young child feeding transition underway?
}

\author{
Phillip Baker ${ }^{1, *}$, Julie Smith ${ }^{1}$, Libby Salmon ${ }^{1}$, Sharon Friel ${ }^{1}$, George Kent ${ }^{2}$, \\ Alessandro lellamo ${ }^{3}$, JP Dadhich ${ }^{4}$ and Mary J Renfrew ${ }^{5}$ \\ 'Health Equity and Governance Group, RegNet School of Regulation and Global Governance, H.C. Coombs \\ Extension Building \#8, Fellows Road, Australian National University, Canberra, ACT 0200, Australia: ${ }^{2}$ Department \\ of Political Science, University of Hawai'i, Honolulu, HI, USA: ${ }^{3}$ Independent, Manilla, Philippines: ${ }^{4}$ Breastfeeding \\ Promotion Network of India, Delhi, India: ${ }^{5}$ Mother and Infant Research Unit, School of Nursing and Health Sciences, \\ University of Dundee, Dundee, UK
}

Submitted 19 January 2016: Final revision received 4 April 2016: Accepted 8 April 2016: First published online 23 May 2016

\begin{abstract}
Objective: The marketing of infant/child milk-based formulas (MF) contributes to suboptimal breast-feeding and adversely affects child and maternal health outcomes globally. However, little is known about recent changes in MF markets. The present study describes contemporary trends and patterns of MF sales at the global, regional and country levels.

Design: Descriptive statistics of trends and patterns in MF sales volume per infant/ child for the years 2008-2013 and projections to 2018, using industry-sourced data. Setting: Eighty countries categorized by country income bracket, for developing countries by region, and in countries with the largest infant/child populations.

Subjects: MF categories included total (for ages 0-36 months), infant (0-6 months), follow-up (7-12 months), toddler (13-36 months) and special (0-6 months).

Results: In 2008-2013 world total MF sales grew by $40 \cdot 8 \%$ from $5 \cdot 5$ to $7 \cdot 8 \mathrm{~kg}$ per infant/child/year, a figure predicted to increase to $10 \cdot 8 \mathrm{~kg}$ by 2018 . Growth was most rapid in East Asia particularly in China, Indonesia, Thailand and Vietnam and was led by the infant and follow-up formula categories. Sales volume per infant/ child was positively associated with country income level although with wide variability between countries.

Conclusions: A global infant and young child feeding (IYCF) transition towards diets higher in MF is underway and is expected to continue apace. The observed increase in MF sales raises serious concern for global child and maternal health, particularly in East Asia, and calls into question the efficacy of current regulatory regimes designed to protect and promote optimal IYCF. The observed changes have not been captured by existing IYCF monitoring systems.
\end{abstract}

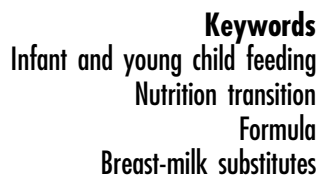

Breast-feeding is important for infant and young child health and development, and for maternal health, in both developed- and developing-country settings ${ }^{(1-3)}$. It is ranked as the single most effective intervention for the prevention of deaths in children under 5 years of age ${ }^{(4)}$. To achieve optimal growth, development and health the WHO recommends that infants should be exclusively breast-fed for the first 6 months of life and thereafter receive nutritionally adequate and safe complementary foods while continuing breast-feeding for up to 2 years of age or beyond ${ }^{(5,6)}$. Although significant progress has been made in some countries, the global exclusive breast-feeding rate improved only marginally from 33\% in
1995 to $37 \%$ in $2014^{(7)}$. Every year an estimated 823000 deaths, or $13.8 \%$ of total deaths, in children under 2 years of age would be prevented if breast-feeding were scaled up to a near-universal level in high-mortality low- and middleincome countries. For mothers, a universal level of breastfeeding in all countries would prevent an estimated 20000 deaths from breast cancer annually ${ }^{(8)}$. Suboptimal infant and young child feeding (IYCF) also incurs higher health system expenditures through increased paediatric and maternal health-care needs ${ }^{(9-11)}$ and productivity-related economic losses of \$US 302 billion or $0 \cdot 49 \%$ of world gross national income annually ${ }^{(12)}$. 
The WHO/UNICEF Global Strategy for Infant and Young Child Feeding commits member countries to implement policies designed to protect, promote and support breastfeeding and to give full effect to the International Code of Marketing of Breast-Milk Substitutes and subsequent World Health Assembly resolutions (hereafter referred to as 'The Code' $)^{(13)}$. These commitments were reaffirmed in 2012, when member countries unanimously adopted the goal of increasing the global exclusive breast-feeding rate ( $<6$ months) to at least $50 \%$ by $2025^{(14)}$. Implementation and monitoring of The Code is further supported by the UN Convention on the Rights of the Child and its monitoring body, the Committee on the Rights of the Child. The Code is a response to long-standing concern that the commercial marketing of breast-milk substitutes (BMS), including milkbased formulas (MF) and other foods represented to be suitable as partial or total replacements of breast milk, contributes significantly to suboptimal $\mathrm{IYCF}^{(13)}$.

Despite these high-level policy commitments, recent market reports indicate that a global MF 'sales boom' is underway $^{(15)}$. This sales boom applies not only to infant formula (for consumption by infants aged 0-6 months) but also to follow-up (7-12 months) and toddler (13-36 months) formulas, which can displace ongoing breast-feeding if marketed and consumed inappropriately. Because products in these latter categories are often branded, packaged and labelled in ways that resemble infant formula, they can be erroneously introduced in the first 6 months of life ${ }^{(16-18)}$. The WHO has long maintained that these milks are unnecessary and unsuitable as $\mathrm{BMS}^{(19)}$.

Such reports are concerning given the well-established evidence that formula-fed children experience poorer health and developmental outcomes than breast-fed children, with additional adverse implications for maternal health. Breast milk is a personalized source of nutrition, providing optimal levels of nutrients in volumes regulated by the mother-child feeding dyad and an array of biological factors critical for normal immunological, gastrointestinal and neurological development ${ }^{(8)}$. MF is an ultra-processed food $^{(20)}$, defined as an industrial formulation of (typically) bovine milk powder, sugars, vegetable oils, vitamins and minerals, and other additives. Although an appropriate food when breast-feeding is contraindicated, MF is prone to microbial contamination (of the formula product, when mixed with contaminated water or through unsterile feeding equipment), industrial contamination (e.g. the 2008 East Asia melamine poisoning crisis), and is implicated in infant malnutrition when practised inappropriately (including under- and over-dilution and under- and over-feeding). Evidence on the health and developmental implications of MF comes from studies comparing never and partially breast-fed $v$. breast-fed infants, including significant increased risks of all-cause mortality, diarrhoea and pneumonia mortality ${ }^{(2)}$, obesity and type 2 diabetes ${ }^{(21)}$, otitis media $^{(22)}$, malocclusion ${ }^{(23)}$, asthma ${ }^{(24)}$ and sudden infant death syndrome ${ }^{(25)}$. Non-breast-fed children also demonstrate significantly lower IQ (intelligence quotient) scores, robust to adjustments for maternal $\mathrm{IQ}^{(26)}$. Formulafeeding affects maternal health primarily due to foregone protective effects of breast-feeding against ovarian cancer, breast cancer and type 2 diabetes ${ }^{(1)}$.

Although the reported MF sales boom could have important public health implications, it is not evidenced in current WHO/UNICEF monitoring systems for IYCF. The existing MF-relevant indicator of 'proportion of children 0-23 months of age who are fed with a bottle' is voluntarily reported, coverage is low and longitudinal data patchy. To address the identified evidence gap the present paper describes recent global trends and patterns in MF sales volumes using market sales data in countries categorized by income level and in developing countries by region. Sales volumes in countries with the largest infant/ child populations are also reported. We conclude with a discussion of the potential factors driving global MF sales and observed variations between regions and countries.

\section{Methods}

\section{Setting and subjects}

The analysis included eighty countries for which data were available, categorized by World Bank income bracket: fifteen lower-middle income countries (L-MIC), twenty-six upper-middle income countries (U-MIC) and thirty-nine high-income countries (H-IC), representing 280220000 infants/children aged 0-36 months in 2013 (Table 1) ${ }^{(27)}$. To ascertain regional trends in MF sales in developing countries, where most of the recent MF market growth has been reported, L-MIC and U-MIC were also categorized by World Bank region (Table 2).

\section{Data sources and measures}

Data from food balance sheets (food supply), household expenditure surveys and food consumption surveys are commonly used to monitor population-level diets ${ }^{(28)}$. However, we were unable to obtain adequate nationallevel, globally comparable, longitudinal data for MF from these sources. Instead, similar to other analyses of global food and beverage markets, we adopted country-level retail sales volume per capita as a proxy measure of consumption ${ }^{(29-31)}$. Data were extracted from country reports sourced from the Euromonitor Passport Global Market Information database for the years 2008-2013 with projections to $2018^{(32)}$. Euromonitor collects these data from trade associations, industry bodies, business press, company financial reports and official government statistics. The data are validated through consultation with people working within industry. Projections are calculated by establishing a historic market trend and then factoring in possible future market changes (e.g. likelihood of recession or government regulation) ${ }^{(32)}$. 
Table 1 Countries included in the analysis, categorized by World Bank income bracket, and population aged 0-36 months in 2013

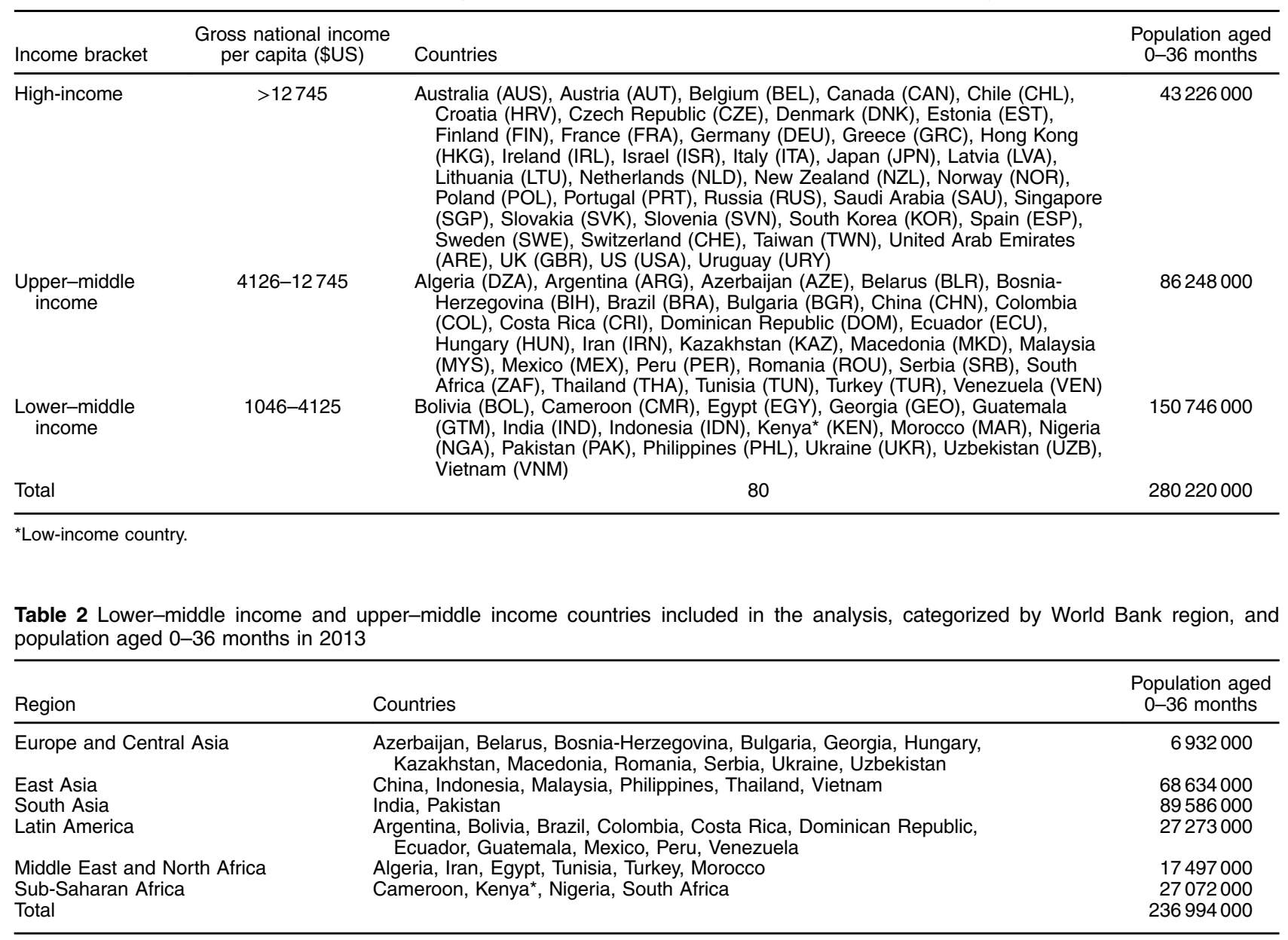

*Low-income country.

To control for country population size differences and growth rates, volumes were converted to kilograms per infant/child, matched to the target age groups of the respective MF product categories defined by Euromonitor. These categories included: total MF (aggregates all product categories; for consumption by infants and children aged 0-36 months), infant formula (IF; 0-6 months), follow-up formula (FUF; 7-12 months), toddler formula (TF; 13-36 months) and special formula (SF; sold for infants with dietary conditions and including soya-based and lactosefree varieties; calculated for infants aged 0-6 months) ${ }^{(32)}$. Infant/child population estimates corresponding to these categories were sourced from the Euromonitor Passport Global Market Information database as derived from official UN and national statistics. Data were unavailable for FUF in the USA and TF in Japan, making the total MF sales figures in these markets an underestimate.

Gross domestic product (GDP) per capita (in international dollars at purchasing power parity to allow for comparability between countries) was adopted as an approximate measure of consumer purchasing power, with data extracted from the World Bank World Development Indicators database for the years 2008-2013 ${ }^{(27)}$.

\section{Data analysis}

Country total MF sales volumes per infant/child in 2013 were plotted against GDP per capita (in international dollars at purchasing power parity for comparability between countries). Country compound annual growth rates for the period 2008-2013 were calculated and plotted against sales volumes in 2013 for the respective categories. Additionally, descriptive statistics were used to describe total MF and category sales volumes and 5-year historical (2008-2013) and projected (2014-2018) growth rates, for each country income category and for the five country markets with the largest infant/child population in each country income category. Sales in L-MIC and U-MIC were also analysed by region.

\section{Results}

Figure 1 shows the relationship between total formula sales per infant/child and log GDP per capita in 2013. Figure 2(a)-(i) shows the relationship between sales volume per infant/child in 2013 and the compound annual growth rate for sales volume per infant/child in the period 


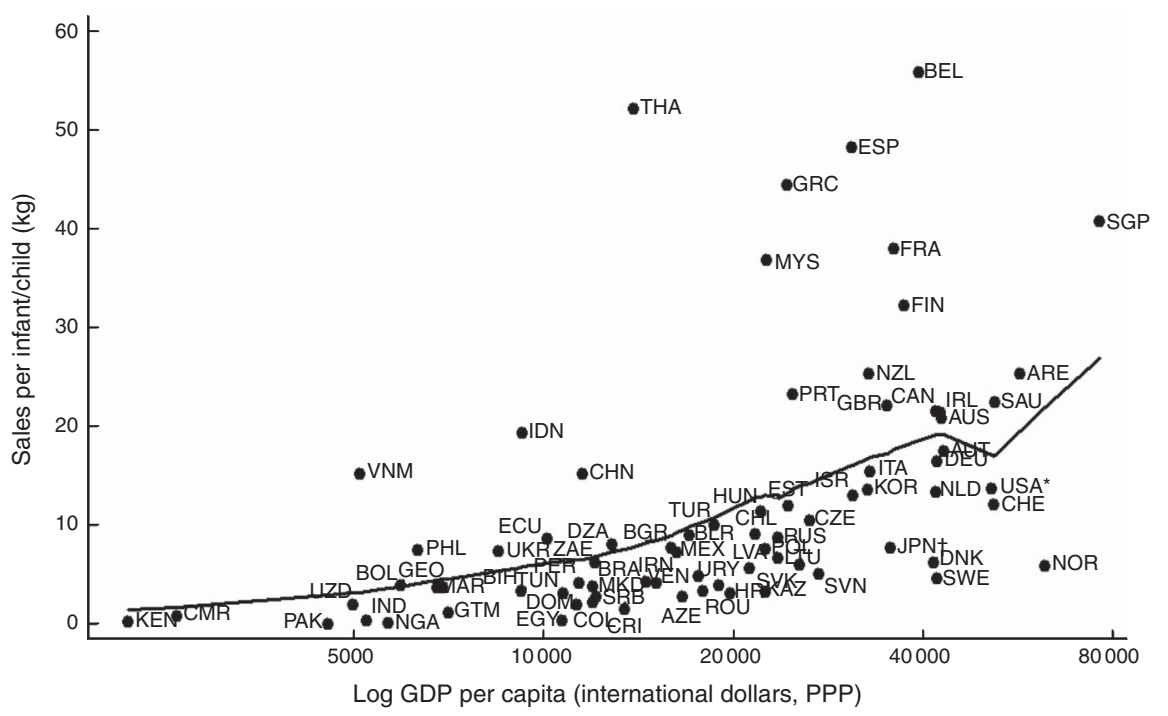

Fig. 1 Total formula retail sales volumes $(\mathrm{kg})$ per infant/child (aged 0-36 months) $v$. log GDP per capita (PPP, international dollars) in 2013 , with fitted values. The fitted line on the graph represents a robust, non-parametric, locally weighted regression describing the smoothed relationship between the variables, generated using the Stata lowess algorithm (set to the default bandwidth of 0.8 , $n$ 79); see Table 1 for country abbreviations; data from Euromonitor Passport Global Market Information database ${ }^{(32)}$. ${ }^{*}$ Volume for USA excludes follow-up formula; tvolume for JPN excludes toddler formula; HKG was excluded as an outlier with $256.9 \mathrm{~kg}$ per infant/child. GDP, gross domestic product per capita at purchasing power parity (PPP) and international dollars to allow for comparability between countries

2008-2013, for the infant, follow-up and toddler formula categories, in countries grouped by income. These demonstrate a positive association between sales volume and country income level, although with wide variability in volumes and growth rates between countries within each income category. For example, Indonesia and Vietnam had considerably higher sales volumes and growth rates in contrast to other L-MIC such as Egypt, India and Pakistan. The UK, Australia, New Zealand and Saudi Arabia had considerably higher sales volumes and growth rates than most other H-IC, particularly Scandinavian and Eastern European countries such as Denmark, Sweden and Croatia.

Table 3 describes MF product category sales volumes in 2013 as well as historic and projected 5-year growth rates for the country income categories and for countries with the largest infant/child populations. Figure 3 demonstrates MF category sales trends for the country income categories. Between 2008 and 2013 the total world MF sales volume grew by $40.8 \%$ from 5.5 to $7.8 \mathrm{~kg}$ per infant/child per year, a rate greatly exceeding GDP growth over the same period. Between 2014 and 2018 this figure is projected to increase by $30.4 \%$ to $10 \cdot 8 \mathrm{~kg}$ per infant/child per year, with growth led by the infant and follow-up categories. The toddler category demonstrated the strongest growth in the 2008-2013 period; however, the infant and follow-up formula categories were more significant in terms of absolute volume growth. The infant and follow-up formula categories are predicted to account for most of world volume growth in 2014-2018.
Much of the recent growth was explained by U-MIC, where total MF sales volume per infant/child grew by $71.7 \%$ in 2008-2013, led by China, Brazil, Peru and Turkey. Growth was also strong in L-MIC led by Indonesia and Vietnam, although with some exceptions (e.g. Indonesia) absolute sales volumes were comparatively low; whereas $19.9 \mathrm{~kg}$ per infant/child of total MF was sold in $\mathrm{H}-\mathrm{IC}$ in 2013 , this figure was only $2 \cdot 8 \mathrm{~kg}$ in L-MIC. Although total MF sales grew in H-IC, many of the largest markets, namely France, Japan, Korea, USA and Russia, underwent negative growth in the infant and follow-up categories. However, many $\mathrm{H}-\mathrm{IC}$ demonstrated strong growth in toddler formula. Hong Kong was an outlier with a total MF volume of $256.9 \mathrm{~kg}$ per infant/child in 2013, and growth of $83.5 \%$ over the 2008-2013 period, likely resulting from sales for informal export into neighbouring China. Some H-IC, for example New Zealand, Australia, Ireland and France, are significant dairy producers and high volumes in these countries may also partly reflect sales for informal export.

Figure 4 shows MF category sales trends in U-MIC and L-MIC by region. Volume growth in all regions has been led by the infant and follow-up formula categories. Follow-up formula sales volumes exceeded infant formula volumes in all regions except Latin America and subSaharan Africa. The rate and scale of change in the East Asia and Pacific region exceeded that of all other regions; in 2008-2013 total MF sales there grew by $72.8 \%$ from 9.8 to $16.9 \mathrm{~kg}$ per infant/child. In $2014-2018$ this figure is projected to increase by $57 \cdot 7 \%$ to $26.6 \mathrm{~kg}$ per infant/child. Four countries, China, Indonesia, Thailand and Vietnam, 

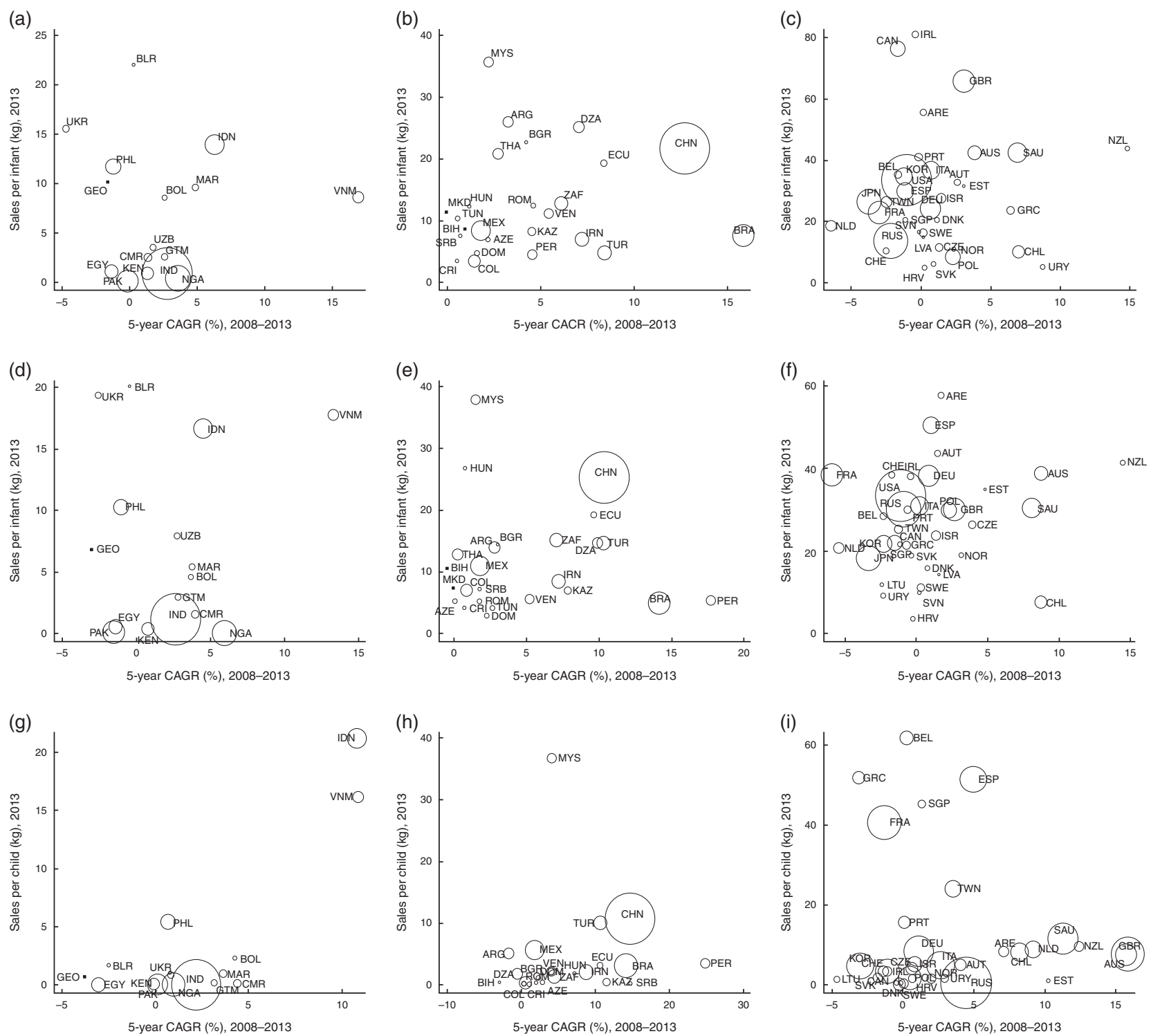

Fig. 2 Formula sales volumes (kg) per infant/child in 2013 v. 5-year compound annual growth rates (CAGR; \%) for 2008-2013, for countries grouped by income category, with weighted markers representing infant/child population sizes: (a) infant formula, L-MIC; (b) infant formula, U-MIC; (c) infant formula, H-IC; (d) follow-up formula, L-MIC; (e) follow-up formula, U-MIC; (f) follow-up formula, H-IC; (g) toddler formula, L-MIC; (h) toddler formula, U-MIC; (i) toddler formula, H-IC. See Table 1 for country abbreviations; data from Euromonitor Passport Global Market Information database ${ }^{(32)}$; population estimates are for infants/children aged 0-6 months for infant formula, 7-12 months for follow-up formula and 13-36 months for toddler formula. Fig. 1(c) excludes JPN and outliers not shown are HKG $(269.3 \mathrm{~kg}, 14.3 \%)$ and FIN $(114.8 \mathrm{~kg},-0.8 \%)$; Fig. 1 (f) outliers not shown are HKG (100.5 kg, $4.9 \%)$ and FIN (72.3 kg, $-0.6 \%)$; Fig. 1(g) excludes UZB; Fig. 1(e) excludes MKD and outlier not shown is THA (68.8 kg, 6.3\%); Fig. 1(i) excludes JPN and USA and outliers not shown are HKG $(298.7 \mathrm{~kg}, 10.7 \%)$ and FIN $(1.3 \mathrm{~kg}, 33.0 \%)$. L-MIC, lower-middle income countries; U-MIC, upper-middle income countries; $\mathrm{H}-\mathrm{IC}$, high-income countries

explained much of the regional growth, with total MF sales growing by $106 \cdot 0,69 \cdot 4,40.0$ and $96.9 \%$, respectively, in 2008-2013. China has undergone the most significant change in formula sales over the period 2008-2013 because of its relatively high category sales volumes and growth rates, but also because of its large infant/child population size. The Philippines is the only country in this region where the market contracted. The Middle East and North Africa region also demonstrated strong volume growth led by Iran and Turkey with total MF growth rates of 53.6 and $80.2 \%$, respectively, in $2008-2013$. The Latin America region demonstrated some heterogeneity; while total MF sales in Brazil and Peru grew by 132.5 and $159.7 \%$, respectively, over the period 2008-2013, for Mexico this figure was just $11.4 \%$. In sub-Saharan Africa the low level of observed growth was led by South Africa, with total MF growth of $37.0 \%$ in 2008-2013. Among all regions, sales volumes and growth rates were lowest in South Asia, with negligible total MF volume growth in India and negative growth in Pakistan. 
Table 3 Formula category consumption volumes $(\mathrm{kg})$ per infant/child in 2013, with 5-year actual and projected growth rates (\%), for country income brackets and the largest country markets by infant/child population size

\begin{tabular}{|c|c|c|c|c|c|c|c|c|}
\hline Markets & $\begin{array}{c}\text { Infant } \\
\text { (0-6 months) }\end{array}$ & $\begin{array}{c}\text { Follow-up } \\
\text { (7-12 months) }\end{array}$ & $\begin{array}{c}\text { Toddler } \\
\text { (13-36 months) }\end{array}$ & $\begin{array}{c}\text { Special } \\
\text { (0-6 months) }\end{array}$ & $\begin{array}{c}\text { Total } \\
\text { (0-36 months) }\end{array}$ & $\begin{array}{c}\text { Total } \Delta 2008- \\
13(\%)\end{array}$ & $\begin{array}{c}\text { Total } \Delta 2014- \\
18(\%)\end{array}$ & $\begin{array}{c}\Delta \text { GDP2008- } \\
13(\%)\end{array}$ \\
\hline $\mathrm{H}-\mathrm{IC}$ & 32.0 & $30 \cdot 0^{*}$ & $14.1 \dagger$ & $6 \cdot 3$ & $19.9 \ddagger$ & $10 \cdot 5$ & 9.9 & $-4 \cdot 2$ \\
\hline USA & 45.4 & - & 5.0 & $16 \cdot 4$ & - & - & - & 1.9 \\
\hline Russia & $13 \cdot 6$ & $30 \cdot 1$ & 0.4 & 3.6 & 8.7 & $-4 \cdot 8$ & $14 \cdot 3$ & $4 \cdot 1$ \\
\hline Japan & $26 \cdot 3$ & $18 \cdot 2$ & - & 2.6 & - & - & - & $2 \cdot 1$ \\
\hline UK & 65.7 & 29.9 & 7.7 & 5.7 & $22 \cdot 0$ & $31 \cdot 3$ & $13 \cdot 0$ & -2.1 \\
\hline France & $22 \cdot 8$ & 38.4 & 40.6 & 4.2 & $37 \cdot 9$ & $-13 \cdot 2$ & $-7 \cdot 4$ & -0.9 \\
\hline U-MIC & $16 \cdot 3$ & $17 \cdot 7$ & 9.2 & 1.0 & 12.0 & $71 . \overline{7}$ & $47 \cdot 3$ & $8.7 \S$ \\
\hline China & 21.7 & $25 \cdot 3$ & 10.7 & 0.2 & $15 \cdot 2$ & $106 \cdot 0$ & 60.0 & $49.1^{\circ}$ \\
\hline Brazil & 7.5 & 4.9 & 3.1 & 0.3 & 4.2 & 132.5 & $28 \cdot 2$ & $9 \cdot 1$ \\
\hline Mexico & 8.3 & 10.9 & 5.6 & 2.0 & $7 \cdot 2$ & 11.4 & $9 \cdot 1$ & 2.9 \\
\hline Iran & 7.0 & 8.4 & 2.0 & 1.4 & $4 \cdot 1$ & $53 \cdot 6$ & $46 \cdot 8$ & $3 \cdot 2$ \\
\hline Turkey & 4.7 & $14 \cdot 7$ & $10 \cdot 0$ & 0.3 & $10 \cdot 0$ & $80 \cdot 2$ & 41.8 & $12 \cdot 8$ \\
\hline L-MIC & 2.9 & 3.4 & 2.5 & 0.2 & 2.8 & 38.8 & 21.6 & 14.5 \\
\hline India & 0.9 & 1.2 & 0.0 & 0.0 & 0.4 & $16 \cdot 2$ & 7.8 & 31.6 \\
\hline Nigeria & 0.4 & 0.0 & 0.0 & 0.0 & 0.1 & 24.0 & $19 \cdot 9$ & $15 \cdot 8$ \\
\hline Pakistan & 0.1 & 0.1 & 0.0 & 0.0 & 0.0 & -2.6 & 1.9 & 6.4 \\
\hline Indonesia & 13.9 & $16 \cdot 6$ & $21 \cdot 2$ & 0.5 & $19 \cdot 3$ & $69 \cdot 4$ & 30.6 & $24 \cdot 7$ \\
\hline Philippines & $11 \cdot 7$ & $10 \cdot 3$ & 5.4 & $1 \cdot 1$ & 7.5 & -0.1 & 4.8 & $18 \cdot 7$ \\
\hline World & $10 \cdot 6$ & $11 \cdot 1^{*}$ & 6.0† & $1 \cdot 2$ & $7.8 \neq$ & $40 \cdot 8$ & 30.4 & -0.9 \\
\hline$\Delta 2008-13(\%)$ & 32.9 & 31.2 & 53.3 & 21.7 & $40.8^{\top}$ & - & - & - \\
\hline$\Delta 2014-18(\%)$ & $27 \cdot 3$ & 29.9 & 33.0 & $23 \cdot 6$ & 30.4 & - & - & - \\
\hline
\end{tabular}

$\Delta$, change; GDP, gross domestic product per capita (at purchasing power parity and constant 2011 international dollars to allow for comparability between countries); H-IC, high-income countries; U-MIC, upper-middle income countries; L-MIC, lower-middle income countries.

Data from Euromonitor Passport Global Market Information database ${ }^{(32)}$.

${ }^{*}$ Excludes USA.

†Excludes Japan.

‡Excludes toddler formula in Japan and follow-up formula in the USA.

$\S$ Excludes Argentina.
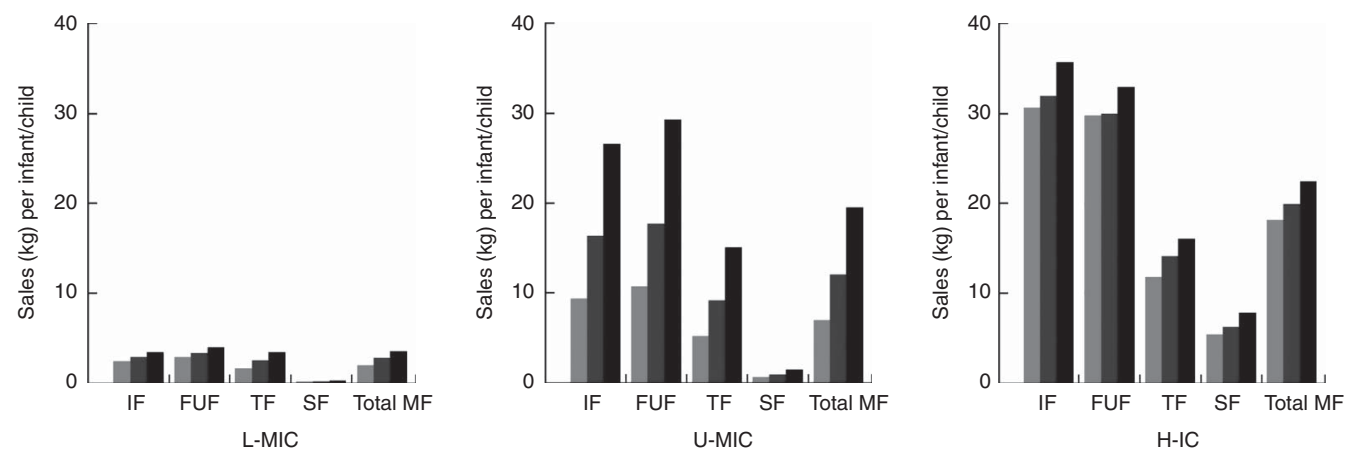

Fig. 3 Formula category sales volumes $(\mathrm{kg})$ per infant/child by country income groups, 2008-2013 ( $\square, 2008$; $\square$, 2013) with projections to 2018 ( $\square$. Data from Euromonitor Passport Global Market Information database ${ }^{(32)}$; population estimates are for infants/children aged 0-6 months for infant formula (IF), 7-12 months for follow-up formula (FUF), 13-36 months for toddler formula (TF), 0-6 months for special formula (SF) and 0-36 months for total milk-based formula (Total MF); countries grouped by World Bank country lending categories; L-MIC, lower-middle income countries; U-MIC, upper-middle income countries; H-IC, highincome countries. Estimates for high-income countries exclude toddler formula in JPN and follow-up formula in the USA

\section{Discussion}

In contrast to stable trends in global exclusive breastfeeding measures ${ }^{(7)}$, the total world MF sales volume grew by $40 \cdot 8 \%$ from $5 \cdot 5$ to $7 \cdot 8 \mathrm{~kg}$ per infant/child in the period 2008-2013. This figure is projected to increase to $10 \cdot 8 \mathrm{~kg}$ per infant/child by 2018 . Volume growth has been led by the infant (0-6 months) and follow-up (7-12 months) formula categories. This indicates that a population-level IYCF transition towards diets higher in MF is not only well underway, but is expected to continue, and in some regions and countries continues apace. Volume growth has occurred most rapidly in the middle-income countries of East and South-East Asia: China, Indonesia, Malaysia, Thailand and Vietnam. UNICEF recently called attention to the 'alarming' decline in breast-feeding rates in this region $^{(33)}$. As home to the world's second largest infant/ child population ( 41 million aged 0-36 months in 2013) the most significant absolute change in IYCF has been in China.

An IYCF transition is not a new phenomenon. For example, a 1982 WHO meta-analysis demonstrated eight stages of change in breast-feeding prevalence and duration with increasing increments of income and 

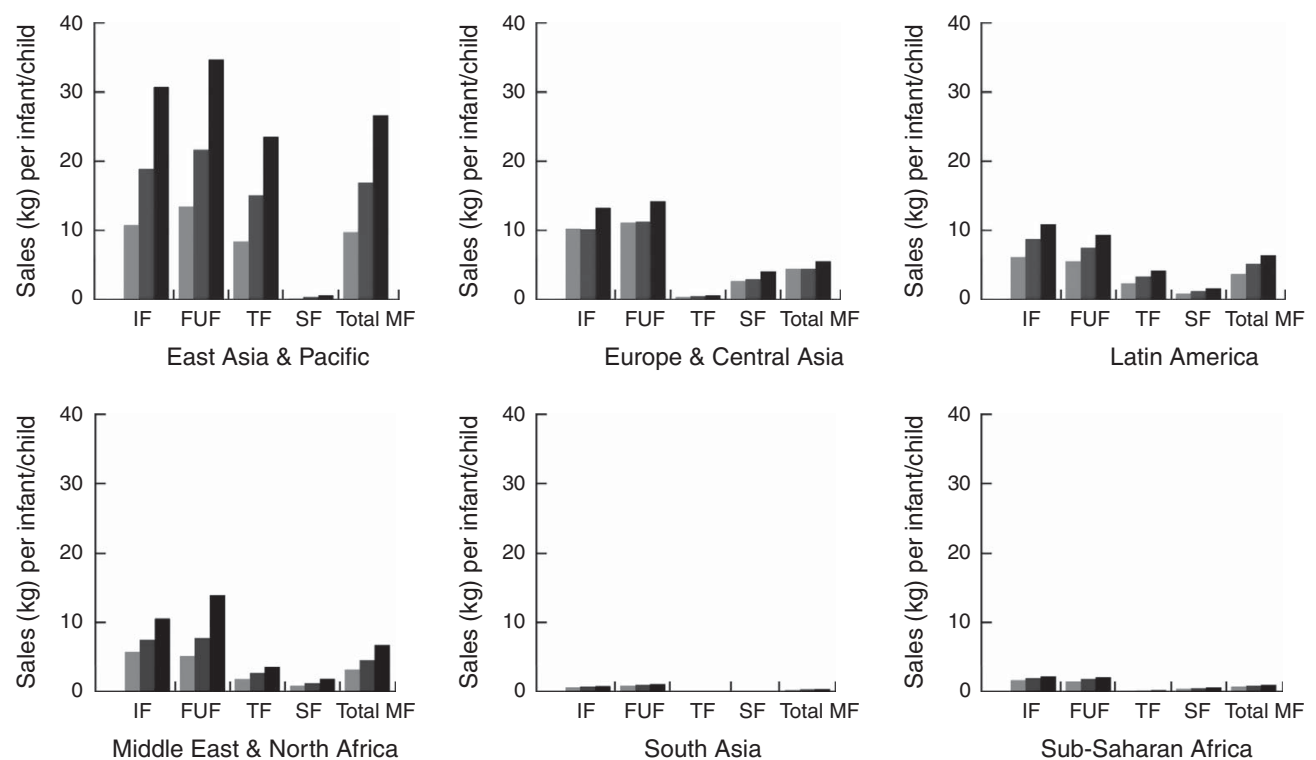

Fig. 4 Formula category sales volumes (kg) per infant/child by region, 2008-2013 ( $\square, 2008$; $\square, 2013$ ) with projections to 2018 ( $\square$ ). Data from Euromonitor Passport Global Market Information database ${ }^{(32)}$; population estimates are for infants/children aged 0-6 months for infant formula (IF), 7-12 months for follow-up formula (FUF), 13-36 months for toddler formula (TF), 0-6 months for special formula (SF) and 0-36 months for total milk-based formula (Total MF). Includes data for lower-middle income countries and upper-middle income countries only (i.e. excludes high-income countries) grouped by World Bank region

urbanization $^{(34)}$. Historical analyses demonstrate a decline in breast-feeding rates in several countries, reaching a historic low in the 1950s-1960s alongside the increasing hospitalization and medicalization of births and more intensive MF marketing ${ }^{(35-37)}$. What appears to be novel is that the contemporary IYCF transition is likely to be characterized by rapid growth in MF sales and ultimately consumption, and that this is potentially unprecedented in terms of the rate and scale of change. Why now? Why especially in East and South-East Asia? The results must be understood against a backdrop of contemporary transformations to economic, social and political systems that are driving changes in the demand and supply of processed foods globally.

A theory of 'nutrition transition' can be adapted to propose that with increasing income growth, urbanization and female labour-force participation (i.e. factors generally associated with economic development) infant/child populations shift to higher levels of MF consumption ${ }^{(38-40)}$. The results support this theory, demonstrating a positive though variable association between MF sales and country income level with the most rapid changes observed in East Asian middle-income countries with high rates of GDP growth. However, sales growth has significantly outpaced GDP growth, suggesting that income change only partly explains the reported results. East Asia also has some of the highest rates of rural-urban migration globally with China and Vietnam expected to urbanize most rapidly in coming decades $^{(41)}$. As with other processed foods, this urbanization is likely to increase population-level accessibility to MF. The large-scale global increase in effective demand for MF may also be explained by the contemporary 'feminization' of East Asia's manufacturing workforce, particularly in the region's export processing and special economic zones where women can comprise between 70 and $90 \%$ of the workforce $^{(42)}$. In the absence of supportive working conditions (e.g. adequate maternity leave, paid lactation breaks, flexible working hours and nursing facilities), formula-feeding can be less time intensive and more convenient than breast-feeding for working mothers . Formula also enables other carers to feed the infant ${ }^{(43,44)}$.

A theory of 'dietary dependency' can be adapted to propose that with global market integration the traditional IYCF systems of developing countries (i.e. predominantly breast-feeding and home-prepared complementary foods) are displaced by, and thus increasingly dependent on, the imports, investments and marketing practices of transnational milk formula corporations (TMFC) ${ }^{(29)}$. This is particularly relevant to IYCF because the biology of breastfeeding means that the form of dependency is extreme when short-term lactation capacity is lost at an individual level (i.e. mammary involution due to bottle-feeding) and when cultural norms are changed (i.e. a shift from 'breastfeeding' to 'formula-feeding' culture) at the population level. Commercial marketing and promotion facilitates this dependency by normalizing formula as an appropriate food for all infants rather than as a specialized food for those unable to breast-feed ${ }^{(45-47)}$. Dependency can impair infant and young child food security when there are disruptions to formula supply, accessibility (including affordability) and capacity to utilize ${ }^{(48)}$.

Four TMFC together controlled $55 \%$ of the global MF market value in 2013: Nestle, Danone, Mead Johnson and 
Abbot Laboratories ${ }^{(15)}$. There are strong incentives for these companies to expand transnationally. MF is highly lucrative with reported net profit margins of $10-20 \%$. The global total MF sales value was \$US 44.8 billion in 2014, projected to reach $\$$ US 70.6 billion by 2019 . In 2014 , the Chinese MF market alone was worth \$US $17 \cdot 8$ billion $^{(12)}$. With stagnating growth in the more heavily regulated high-income markets, developing Asian countries are seen as new growth opportunities given their rising income levels, young and growing populations, and openness to foreign investment ${ }^{(49)}$. Additionally, TMFC often donate large quantities of MF to countries in post-disaster situations, potentially undermining breast-feeding in this context. This is most pertinent for the Asia-Pacific region, the world's most disaster prone ${ }^{(50)}$.

Approximately $10 \%$ of MF sales is spent on marketing and promotion ${ }^{(51)}$. Extrapolating this to the reported global sales value we estimate a global MF marketing expenditure of \$US 4.48 billion in 2014. MF is marketed directly to consumers through online and print advertising, and indirectly through health systems, sponsorship of professional organizations and lobbying of policy makers ${ }^{(12)}$. Such marketing can powerfully influence social norms about IYCF through inter alia portraying MF as a symbol of modernity, as comparable or superior to breast milk, and formula-feeding as extensively practised $^{(46)}$. Strong evidence implicates MF marketing during the perinatal period, especially the distribution of free or low-cost samples and maternity discharge packs to healthcare workers and mothers, with reduced rates of breastfeeding initiation, duration and exclusivity ${ }^{(12)}$. This underpins the requirement of the Baby Friendly Hospitals Initiative (BFHI) that hospitals are free of intrusive efforts to market $\mathrm{BMS}^{(37)}$. Evidence demonstrates that the BFHI has had a significant positive effect on exclusive breastfeeding rates at national and global levels. However, the most recent monitoring data indicate that just $27.5 \%$ (representing 21328 hospitals) of all maternities worldwide had ever been designated as baby friendly, representing $8.5 \%$ of those in industrialized countries and $31 \%$ in less developed countries ${ }^{(52)}$.

The strong growth in the follow-up formula and toddler formula categories observed in the present analysis is concerning. Since 1986 the WHO has maintained that follow-up formula is both unnecessary and unsuitable as a BMS from 6 months of age onwards. Further, existing formulations can result in excessive protein intake and inadequate intakes of essential fatty acids, vitamins and minerals ${ }^{(19)}$. Sales growth in these categories may reflect a market segmentation strategy whereby TMFC are exploiting the erroneous perception that breast-feeding applies to the first 6 months only, and not to continued breastfeeding ${ }^{(53)}$. The branding, packaging and labelling of follow-up formula and toddler formula products frequently resembles and is commonly mistaken for infant formula ${ }^{(16,18,45)}$. This can circumvent MF regulations focused exclusively on the 0-6 month age bracket and may be exacerbated when IYCF policies and programmes emphasize exclusive breast-feeding only, and not ongoing breast-feeding ${ }^{(54)}$.

The variability in the observed GDP-sales relationship demonstrates that an IYCF transition is not an inevitable consequence of economic growth. Several middle-income and high-income countries have achieved comparatively low sales levels. Government decisions concerning the regulation of MF markets, as well as those concerning breast-feeding protection, promotion and support, are likely to be important determinants of country-level differences. For example, one analysis found a significant positive association between indicators of country-level implementation of the Global Strategy for Infant and Young Child Feeding and trends in exclusive breastfeeding and breast-feeding duration over a 20-year period $^{(55)}$. Further research is required to ascertain associations between these same measures and global MF sales patterns. Nevertheless, we now explore some of the most important policy and regulatory factors likely to be shaping MF markets.

Weak and inadequately implemented MF marketing regulation is likely to be a key explanatory factor in the observed differences in between-country sales. Violations of the WHO/UNICEF International Code of Marketing of Breast-milk Substitutes and subsequent resolutions (The Code) by formula companies are common in both developed and developing countries ${ }^{(56-58)}$. The Code is not legally binding under international law (adopted under Article 23 of the WHO constitution), nor is it enforceable under domestic law unless adopted into national legislation $^{(56)}$. According to the latest WHO monitoring report only thirty-seven (19\%) out of 199 reporting countries had adopted all of the recommendations into law, just sixtynine $(35 \%)$ had fully prohibited the advertising of BMS, and forty-five (23\%) had a functioning implementation and monitoring system ${ }^{(56)}$. In those with active monitoring systems many are under-resourced and do not impose legal sanctions against industry violators ${ }^{(58)}$. Internet marketing channels, including social media, are new sources of non-compliance ${ }^{(59)}$. In China, undoubtedly the engine of the contemporary global MF sales boom, many provisions of The Code were adopted into legislation in 1995. However, the legislative scope is outdated and applies to the 0-4 month age category only, implementation and enforcement have been reported as weak and poorly coordinated, and Code violations appear to be common and widespread ${ }^{(12,57,60)}$. In contrast, regulatory responses appear to have constrained formula markets in several countries. For example, sales volumes and growth in India are negligible and at least partly explained by that Government's full adoption of The Code into legislation with a scope of $0-24$ months of age ${ }^{(45,56)}$. Another country with comparatively low levels of MF sales is Brazil where The Code is fully adopted into legislation covering 
0-36 months of age, is rigorously monitored and has been regularly strengthened in response to violations (although sales are now beginning to grow rapidly) ${ }^{(12,56)}$.

Maternity protection regulations determine the compatibility of IYCF choices with formal maternal employment. In the context of absent or ineffective regulation, the choice of whether to formula-feed or breast-feed is not a true choice. For many, formula-feeding is the only choice if the alternative is the loss of employment and income. Indeed, it is more common for new mothers to stay employed and use BMS rather than leave work or school in order to breast-feed ${ }^{(12)}$. This not only discriminates against the combined economic and reproductive rights of women but also against the rights of the child to adequate nutrition. The Maternity Protection Convention of the International Labour Organization protects against maternity discrimination and provides for adequate paid maternity leave (minimum of 14 but preferably 18 weeks at two-thirds of earnings), the right to continue breastfeeding on return to work, paid nursing breaks and access to appropriate and hygienic nursing facilities. Yet the most recent monitoring report found that most countries in Asia (81\%), the Middle East (92\%) and Latin America (79\%) fail to meet the minimum leave and earnings standards. Just $31 \%$ have legislated the mandatory provision of nursing facilities. Subsequently, 830 million (68\%) working women worldwide do not have adequate maternity protection, of whom $80 \%$ live in Africa and Asia. Just 330 million (28.4\%) are legally entitled to receive cash payments in the event of childbirth ${ }^{(61)}$.

Free trade agreements, which have been extensive in East Asia in recent decades, reduce barriers to the movement of investments, production capacity, raw materials and final products across borders ${ }^{(49)}$. These processes enable TMFC to more easily expand their operations through the establishment of transnational networks of affiliate firms and highly coordinated global supply chains $^{(62)}$. Contemporary large-scale increases in dairy production for export in many countries, particularly New Zealand, have provided TMFC with a ready supply of milk powder, the primary ingredient used in formula production $^{(53,62)}$. The liberalization of trade in retail services has also spurred the 'supermarketization' of developing countries since the late 1990s, creating new MF distribution channels. In this context, government regulators face the paradoxical challenge of balancing the investments and thus opportunities for economic development TMFC provide against the public health implications of those investments. This is especially the case when companies such as Nestle and Danone are among the largest operating in developing countries and when government agencies have only limited capacity to weigh the public health implications ${ }^{(49)}$.

In some countries conflicts in government policy objectives exist. For example, more than half of MF purchases in the USA are by the Government through its Special
Supplemental Nutrition Program for Women, Infants, and Children $^{(63)}$. In China, MF consumption is promoted by government subsidies with the aim of developing the domestic industry including the development of new formula products ${ }^{(51)}$. The MF industry also generates large tax revenues, creating an incentive to maintain or encourage market growth. This is especially likely when the significant economic value of reproductive services, including breastfeeding, is excluded from national accounting systems ${ }^{(51)}$. In East Asia's so-called 'productivist welfare states' we hypothesize that MF may be viewed by policy makers as instrumental to female labour-force participation and therefore to economic development, although this requires further investigation ${ }^{(64)}$.

There are several limitations of the current analysis. The market data used capture sales volume only, an imperfect measure of consumption because it does not capture BMS products distributed through informal food systems or wastage (i.e. the proportion of MF sold but not consumed). Sales volumes may not accurately reflect domestic consumption in some markets due to high sales for informal export. For example, in Hong Kong total MF was $256.9 \mathrm{~kg}$ per infant/child in 2013 reflecting cross-border purchases by mainland Chinese consumers. High sales volumes in several high-income countries (e.g. New Zealand) also partly reflect informal cross-border trade. As described elsewhere, Euromonitor Passport is not a scholarly database and the data have similar limitations to official government trade and economic statistics ${ }^{(29)}$. The data have not been validated from a nutritional standpoint through, for example, comparisons with household expenditure or food consumption surveys. However, these data have several merits: their abundance, that they are not subject to recall bias (i.e. in contrast with survey data) and that they have been consistently reported across countries and time using standardized measures ${ }^{(29)}$. Lack of comparable longitudinal data prevented analysis of the relationship between MF consumption and breast-feeding prevalence and duration. Thus there is an implicit assumption in the present analysis that MF displaces breast milk in infant and young child diets, rather than reflecting the potential substitution of MF for other BMS such as animal milks. Finally, we have not reported within-country MF sales patterns although a 'social transition' inverse to breast-feeding is likely, with formula-feeding initially most prevalent among high-income groups and then in lowincome groups over the course of a country's economic and social development ${ }^{(34)}$.

\section{Conclusions}

A global population-level IYCF transition towards diets higher in milk-based formulas, especially infant and follow-up formulas consumed in the first year of life, is well underway, is expected to continue, and in some 
regions and countries continues apace. While the concept of such a transition is not new, the observed rapidity in growth and volumes per infant/child is unprecedented. This transition is most evident in the middle-income countries of East Asia, particularly China, Indonesia, Malaysia, Thailand and Vietnam. Because of the large infant/child population in this region, regulatory decisions there concerning IYCF are likely to have an important impact on global infant, child and maternal health over coming decades. The results also raise serious concern that the rapid changes observed are not being captured in a timely manner by existing international IYCF monitoring systems. Important questions must also be raised about the efficacy of existing policy and regulatory regimes intended to protect the health of children and mothers and to prevent unethical formula marketing. As described elsewhere, greater political priority, strengthened governance mechanisms and strategic actions for IYCF are urgently needed $^{(47,53,54,58)}$. New institutions established by WHO/ UNICEF including the Global Breastfeeding Advocacy Initiative and the Network for Global Monitoring and Support for Implementation of the International Code (NetCode) may provide important platforms for coordinating global action ${ }^{(47)}$. The present analysis affirms a need for renewed efforts towards the implementation, monitoring and enforcement of The Code, including stronger accountability mechanisms for governments and industry.

\section{Acknowledgements}

Acknowledgements: The authors would like to thank Dr Adriano Cattaneo for his valuable feedback on the draft manuscript. Financial support: P.B. was employed through an Australian Research Council Discovery Project (number 130101478). This analysis was unfunded. Data were sourced from Euromonitor International through an institutional license at the Australian National University. Conflict of interest: None. Authorship: P.B. proposed the analysis, sourced and analysed the data, and wrote the first draft of the manuscript. P.B., J.S., L.S. and S.F. contributed to the initial conceptualization of the analysis and refinement of the method. J.S. and P.B. coordinated inputs from co-authors. L.S. assisted with sourcing key references and data analysis. All authors contributed to the interpretation of the results and ongoing iterations of the paper, and approved the final manuscript. Ethics of buman subject participation: Not applicable.

\section{References}

1. Chowdhury R, Sinha B, Sankar MJ et al. (2015) Breastfeeding and maternal health outcomes: a systematic review and meta-analysis. Acta Paediatr 104, 96-113.

2. Sankar MJ, Sinha B, Chowdhury R et al. (2015) Optimal breastfeeding practices and infant and child mortality: a systematic review and meta-analysis. Acta Paediatr 104, $3-13$.

3. Grummer-Strawn LM \& Rollins N (2015) Summarising the health effects of breastfeeding. Acta Paediatr 104, 1-2.

4. Jones G, Steketee RW, Black RE et al. (2003) How many child deaths can we prevent this year? Lancet 362, 65-71.

5. World Health Organization \& UNICEF (2003) Global Strategy for Infant and Young Child Feeding. Geneva: WHO.

6. World Health Organization (2013) Essential Nutrition Actions: Improving Maternal, Newborn, Infant and Young Child Health and Nutrition. Geneva: WHO.

7. World Health Organization (1995-2014) World Health Statistics. Geneva: WHO.

8. Victora CG, Bahl R, Barros AJD et al. (2016) Breastfeeding in the 21st century: epidemiology, mechanisms, and lifelong effect. Lancet 387, 475-490.

9. Bartick M, Stuebe AM, Schwarz EB et al. (2013) Cost analysis of maternal disease associated with suboptimal breastfeeding. Obstet Gynecol 122, 111-119.

10. Pokhrel S, Quigley M, Fox-Rushby J et al. (2014) Potential economic impacts from improving breastfeeding rates in the UK. Arch Dis Child 100, 334-340.

11. Smith JP, Thompson JF \& Ellwood DA (2002) Hospital system costs of artificial infant feeding: estimates for the Australian Capital Territory. Aust N Z J Public Health 26, 543-551.

12. Rollins NC, Bhandari N, Hajeebhoy N et al. (2016) Why invest, and what it will take to improve breastfeeding practices? Lancet 387, 491-504.

13. World Health Organization (1981) International Code of Marketing of Breastmilk Substitutes. Geneva: WHO.

14. World Health Organization (2013) Comprehensive Implementation Plan on Maternal, Infant and Young Child Nutrition. Geneva: WHO.

15. Euromonitor International (2013) Babyfood Bucks Global Recession and Offers Positive Growth Prospects. London: Euromonitor International.

16. Berry N, Jones S \& Iverson D (2011) Circumventing the WHO Code? An observational study. Arch Dis Child 97 , 320-325

17. Berry N, Jones S \& Iverson D (2010) It's all formula to me: women's understandings of toddler milk ads. Breastfeed Rev 18, 21-30.

18. Cattaneo A, Pani P, Carletti C et al. (2014) Advertisements of follow-on formula and their perception by pregnant women and mothers in Italy. Arch Dis Child 100, 323-328.

19. World Health Organization (2013) Information Concerning the Use and Marketing of Follow-Up Formula. Geneva: WHO.

20. Ministry of Health of Brazil (2014) Dietary Guidelines for the Brazilian Population, 2nd ed. Brasilia: Ministry of Health.

21. Horta BL, Loret de Mola C \& Victora CG (2015) Long-term consequences of breastfeeding on cholesterol, obesity, systolic blood pressure and type 2 diabetes: a systematic review and meta-analysis. Acta Paediatr 104, 30-37.

22. Bowatte G, Tham R, Allen KJ et al. (2015) Breastfeeding and childhood acute otitis media: a systematic review and metaanalysis. Acta Paediatr 104, 85-95.

23. Peres KG, Cascaes AM, Nascimento GG et al. (2015) Effect of breastfeeding on malocclusions: a systematic review and meta-analysis. Acta Paediatr 104, 54-61.

24. Lodge CJ, Tan DJ, Lau MXZ et al. (2015) Breastfeeding and asthma and allergies: a systematic review and meta-analysis. Acta Paediatr 104, 38-53.

25. Hauck FR, Thompson JM, Tanabe KO et al. (2011) Breastfeeding and reduced risk of sudden infant death syndrome: a meta-analysis. Pediatrics 128, 103-110.

26. Horta BL, Loret de Mola C \& Victora CG (2015) Breastfeeding and intelligence: a systematic review and metaanalysis. Acta Paediatr 104, 14-19. 
27. World Bank (2014) World Development Indicators. http://data. worldbank.org/data-catalog/world-development-indicators (accessed December 2014).

28. Vandevijvere S, Monteiro C, Krebs-Smith S et al. (2013) Monitoring and benchmarking population diet quality globally: a step-wise approach. Obes Rev 14, 135-149.

29. Stuckler D, McKee M, Ebrahim S et al. (2012) Manufacturing epidemics: the role of global producers in increased consumption of unhealthy commodities including processed foods, alcohol, and tobacco. PLoS Med 9, e1001235.

30. Basu S, McKee M, Galea G et al. (2013) Relationship of soft drink consumption to global overweight, obesity, and diabetes: a cross-national analysis of 75 countries. Am J Public Health 103, 2071-2077.

31. Baker P \& Friel S (2014) Processed foods and the nutrition transition: evidence from Asia. Obes Rev 15, 564-577.

32. Euromonitor International (2014) Euromonitor Passport Global Market Information Database. London: Euromonitor International.

33. UNICEF (2012) UNICEF Rings Alarm Bells as Breastfeeding Rates Plummet in East Asia. http://www.unicef.org/media/ media_62337.html (accessed September 2014).

34. World Health Organization (1982) The prevalence and duration of breast-feeding: a critical review of available information. World Health Stat Q 35, 92-116.

35. Wright AL \& Schanler RJ (2001) The resurgence of breastfeeding at the end of the second millennium. J Nutr 131, issue $2,421 \mathrm{~S}-425 \mathrm{~S}$.

36. Smith J (2007) The contribution of infant food marketing to the obesogenic environment in Australia. Breastfeed Rev 15, 23-35.

37. Kaplan DL \& Graff KM (2008) Marketing breastfeeding reversing corporate influence on infant feeding practices. J Urban Health 85, 486-504.

38. Drewnowski A \& Popkin BM (1997) The nutrition transition: new trends in the global diet. Nutr Rev 55, 31-43.

39. Popkin BM, Adair LS \& Ng SW (2012) Global nutrition transition and the pandemic of obesity in developing countries. Nutr Rev 70, 3-21.

40. Hawkes C (2006) Uneven dietary development: linking the policies and processes of globalization with the nutrition transition, obesity and diet-related chronic diseases. Glob Health 2, 4

41. United Nations Human Settlements Programme (2013) Planning and Design for Sustainable Urban Mobility: Global Report on Human Settlements 2013. Nairobi: UN-HABITAT.

42. International Labour Organization Regional Office for Asia and the Pacific \& Asian Development Bank (2011) Women and Labour Markets in Asia: Rebalancing for Gender Equality. Bangkok: ILO.

43. Smith J \& Forrester R (2013) Who pays for the health benefits of exclusive breastfeeding? An analysis of maternal time costs. J Hum Lact 29, 547-555.

44. Ricci JA, Jerome NW, Sirageldin I et al. (1996) The significance of children's age in estimating the effect of maternal time use on children's well-being. Soc Sci Med 42, 651-659.

45. Brady JP (2012) Marketing breast milk substitutes: problems and perils throughout the world. Arch Dis Child 97, 529-532.
46. Piwoz EG \& Huffman SL (2015) The impact of marketing of breast-milk substitutes on WHO-recommended breastfeeding practices. Food Nutr Bull 36, 373-386.

47. McFadden A, Mason F, Baker J et al. (2016) Spotlight on infant formula: coordinated global action needed. Lancet 387, 413-415.

48. Salmon L (2015) Food security for infants and young children: an opportunity for breastfeeding policy? Int Breastfeed J 10, 1.

49. Baker P, Kay A \& Walls H (2014) Trade and investment liberalization and Asia's noncommunicable disease epidemic: a synthesis of data and existing literature. Glob Health 10, 66.

50. Binns CW, Lee MK, Tang L et al. (2012) Ethical issues in infant feeding after disasters. Asia Pac J Public Health 24, 672-680.

51. Smith J (2015) Markets, breastfeeding and trade in mothers' milk. Int Breastfeed J 10, 9.

52. Labbok MH (2012) Global baby-friendly hospital initiative monitoring data: update and discussion. Breastfeed Med 7, 210-222.

53. Kent G (2015) Global infant formula: monitoring and regulating the impacts to protect human health. Int Breastfeed J 10, 6 .

54. UNICEF (2013) Breastfeeding on the Worldwide Agenda: Findings from a Landscape Analysis on Political Commitment for Programmes to Protect, Promote and Support Breastfeeding. New York: UNICEF.

55. Lutter CK \& Morrow AL (2013) Protection, promotion, and support and global trends in breastfeeding. Adv Nutr 4, 213-219.

56. World Health Organization (2011) Country Implementation of the International Code of Marketing of Breast-milk Substitutes: Status Report 2011. Geneva: WHO.

57. Liu A, Dai Y, Xie X et al. (2014) Implementation of international code of marketing breast-milk substitutes in China. Breastfeed Med 9, 467-472.

58. Save the Children (2015) Breastfeeding: Policy Matters. Identifying Strategies to Effectively Influence Political Commitment to Breastfeeding: A Review of Six Country Case Studies. London: Save the Children.

59. Abrahams SW (2012) Milk and social media: online communities and the international code of marketing of breastmilk substitutes. J Hum Lact 28, 400-406.

60. Shetty P (2014) Indonesia's breastfeeding challenge is echoed the world over. Bull World Health Organ 92, 234-235.

61. International Labour Organization (2014) Maternity and Paternity at Work Law and Practice across the World. Geneva: ILO.

62. Smith J, Galtry J \& Salmon L (2014) Confronting the formula feeding epidemic in a new era of trade and investment liberalisation. J Aust Polit Econ 73, 132-171.

63. Kent G (2006) WIC's promotion of infant formula in the United States. Int Breastfeed J 1, 8.

64. Baker P, Kay A \& Walls H (2015) Strengthening trade and health governance capacities to address non-communicable diseases in Asia: challenges and ways forward. Asia Pac Policy Stud 2, 310-323. 